\title{
The developmental process during metamorphosis that results in wing reduction in females of three species of wingless-legged bagworm moths, Taleporia trichopterella, Bacotia sakabei and Proutia sp. (Lepidoptera: Psychidae)
}

\author{
SHUHEI NIITSU ${ }^{1}$ and YUKIMASA KOBAYASHI ${ }^{2}$ \\ ${ }^{1}$ Department of Natural History, Graduate School of Sciences and ${ }^{2}$ Laboratory of Systematic Zoology, Department of Biological \\ Science, Graduate School of Sciences and Engineering, Tokyo Metropolitan University, 1-1 Minami-Ohsawa, \\ Hachioji-shi 192-0397, Japan; e-mail: shu-30@aioros.ocn.ne.jp
}

Key words. Psychidae, wingless-legged bagworm moth, wing reduction, apoptosis

\begin{abstract}
There are several evolutionary grades of wing reduction in female bagworm moths of the family Psychidae. In this family, female adults of Taleporia trichopterella, Bacotia sakabei and Proutia sp. have vestigial wings, although as pupae they have small wings. Consequently, these species (usually called wingless-legged bagworm moths), are intermediate between the two extremes of females with normal wings and those with no wings. Using light and electron microscopy, the processes of wing development during the last-larval instar and wing degeneration during the pupal stage was investigated in these species. Female wing imaginal discs proliferated during the last-larval instar, but diminished due to apoptosis in the prepupal stage of the last instar. In the pupal stage, degenerate cells were observed between the epithelia of the degenerating wing discs of the female. The presence of these cells is associated with apoptotic cell death. These observations suggest that female-specific wing degeneration caused by apoptosis occurs in two steps in these bagworm moths, i.e. in the larval and pupal stages. Such a process of wing reduction has not been previously reported in holometabolous insects, and is reported here for the first time in bagworm moths.
\end{abstract}

\section{INTRODUCTION}

The acquisition of flight capability is one of the most important events in insect evolution (Roff, 1990; Sattler, 1991; Wagner \& Liebherr, 1992; Andersen, 1997). Within Pterygota, adults with reduced or missing wings are secondary and the loss of wings occurred independently in various insect lineages. In Lepidoptera, femalespecific wing degeneration occurs in many groups, i.e., brachypterous or apterous forms are known in 25 families (Sattler, 1991).

In the family Psychidae, which is comprised of nearly 1000 species globally (Davis \& Robinson, 1999), adult females are usually wingless, but the females of primitive lineages have normal wings (Saigusa, 1962). The larvae of this family usually construct a larval case using dead leaves and small twigs, which is why they are called bagworm moths. Therefore, it is assumed that body structure and behaviour have evolved in parallel with each other. Saigusa (1962) graded species of the family Psychidae as $\alpha, \beta, \gamma 1, \gamma 2$, and $\delta$ according to the degree of wing and leg reduction in the female, oviposition behaviour and morphology of the ovipositor (Fig. 1). The features of these four evolutionary grades and 2 sub-grades of wing and leg reduction in females are as follows. $\alpha$-Grade has well developed and functional wings and legs. $\beta$-Grade has degenerate wings and non functional, well developed but short legs, and at emergence the adult female moults outside the larval case. $\gamma 1$-Grade has the same degree of wing and leg reduction as the $\beta$-grade, but the adult female moults in the larval case. $\gamma 2$-Grade has the same degree of wing reduction as the $\beta$-grade and $\gamma 1$-grade, but the end of the abdominal segments of adult female remains in the larval case (Fig. 1. $\gamma 2$ ). $\delta$-Grade lacks wings, has degenerate legs and the adult female is vermiform. Hence, the wingless-legged $\beta$-, $\gamma 1-$ and $\gamma 2$-grades are intermediate between the two extremes; $\delta$-grade with normal wings and $\delta$-grade with no wings. Although the process of wing development in holometabolous insects has been well studied, especially in Drosophilla melanogaster, Manduca sexta and Bombyx mori (Fristrom et al., 1977; Milner et al., 1984; Kawasaki \& Iwashita, 1987; Nardi at al., 1987), studies on the mechanism of wing reduction in lepidopteran insects are limited (Fedotov, 1939; Nüesch, 1947; Nardi et al., 1991; Niitsu, 2001, 2003; Lobbia et al., 2003). The reason for this is partly attributable to the difficulty of rearing wild species in the laboratory.

Niitsu (2003) investigated the process of wing reduction in the bagworm moth, Eumeta variegata, the female of which is completely wingless and lacks legs, and ranked as $\delta$-grade. In this species, the minute wing discs of the female larvae neither grow nor metamorphose, and disappear during the prepupal stages. Nüesch (1947) also reported the process of wing reduction in a winglesslegged bagworm moth, Fumea casta ranked as $\gamma 2$-grade, which according to Saigusa (1962). Nüesch presented some fine observations on wing reduction in this species. This information is still valuable, but many questions remain about the ultrastructure of wing reduction. Therefore, it is important to observe this process under transmission electron microscopy (TEM) in individuals of grades other than $\delta$. 


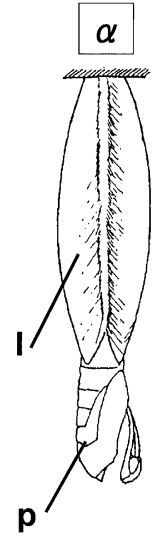

Ancestral grade (Diplodoma)
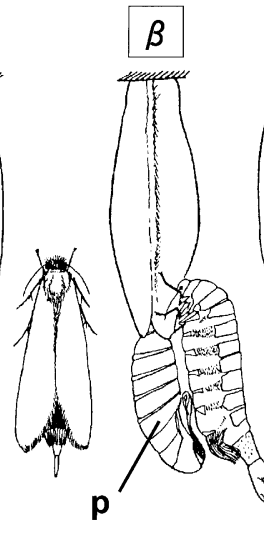

Taleporia

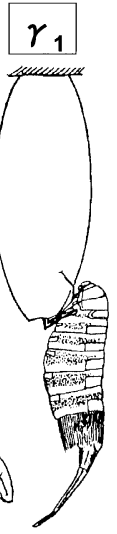

Bacotia

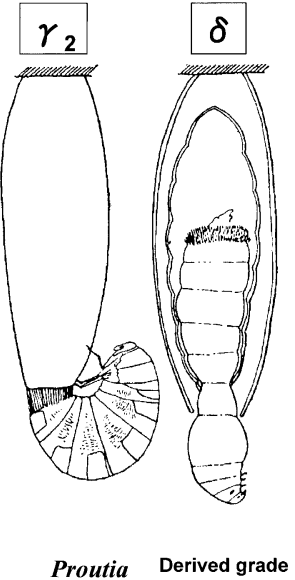

(Eumeta)
Fig. 1. Schematic representations of female adult bagworm moths, modified from Saigusa (1962). In this study three species belonging to $\beta$-, $\gamma 1$ - and $\gamma 2$-grades were used. These three species show intermediate stages in wing reduction in which $\alpha$ is the most ancestral and $\delta$ is the most derived grade. 1 - larval case; $\mathrm{p}$ - pupal exuviae.

In this study, the process of wing reduction in the wingless-legged species, Taleporia trichopterella, belonging to the $\beta$ grade, Bacotia sakabei, to $\gamma 1$-grade, and Proutia sp., to $\gamma 2$-grade, whose females have very small wings (Fig. 2), is described. Furthermore, pupae of these females also have vestigial wings (Figs 3, 4). The morphological changes during the last larval and pupal stages were also compared from a histological perspective. This is the first report demonstrating that the degeneration of wing discs occurs in two steps in the prepupal stage of the last instar and the pupal stage.

\section{MATERIAL AND METHODS}

\section{Insect samples}

The three species of wingless-legged bagworm moths used in this study, Taleporia trichopterella, Bacotia sakabei and Proutia sp., reflect the taxonomic diversity of Psychidae. These three species are univoltine moths, but precise information about their life history, including the number of larval instars, is unknown.

\section{Collection of larvae}

Several last-instar larvae of Taleporia trichopterella, collected in Wakayama Prefecture in March 2004, Bacotia sakabei, collected in Aichi Prefecture in September 2003, and Proutia sp., collected in Yamanashi Prefecture in May of 2004 (all in Japan), were kept in an incubator (14L : 10D) at $20^{\circ} \mathrm{C}$ for a few weeks. The following criteria were used for the identification of females: (1) Pupation in females of all three species occurs later than in males. (2) There is no overlap between males and females in the time of pupation in B. sakabei and T. trichopterella. (3) The mature larvae of Proutia sp. are easily sexed on the basis of their external morphology (Fig. 5). In order to check whether a last-instar larva is a prepupa, its larval case was opened with scissors following the criteria of Entwistle (1963). During the prepupal stage, the last-instar larva of Eumeta variegata turns its head downwards before pupation (Niitsu, 2003). Thus, the change in head direction is also a criterion for discriminating between a last-instar larva and a prepupa. All three
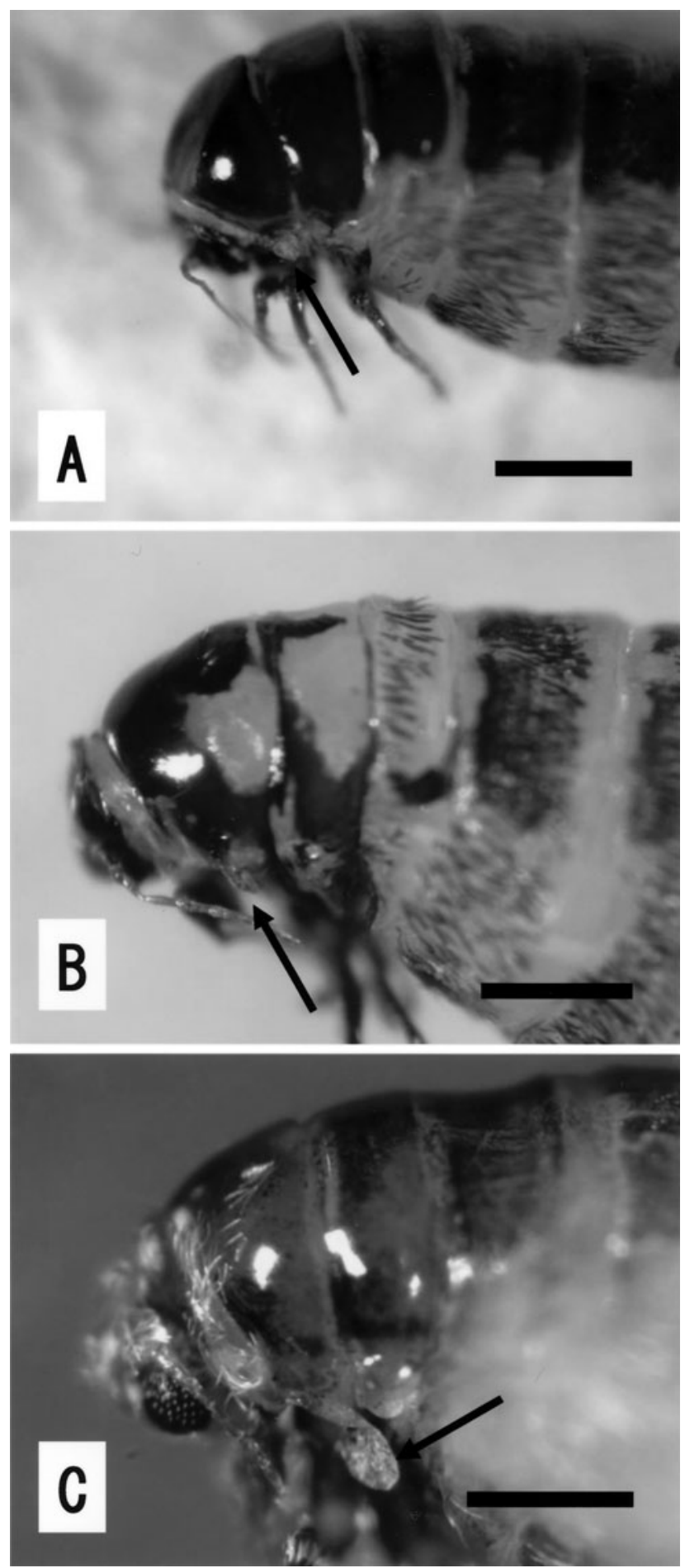

Fig. 2. Thoracic segments of female adults of wingless-legged bagworm moths showing external vestiges of forewings (males have normal wings). Arrows indicate the vestigial wings in the three species. A - Taleporia trichopterella; B - Bacotia sakabei; C - Proutia sp. Scale bars: $500 \mu \mathrm{m}$.

species and both sexes spend about 5 days in the prepupal period, when the gut is purged prior to pupation. At least three female last-instar larvae, prepupae, and pupae of each species were fixed. This study focused mainly on the female forewings of the three species. Only the male wing lobes of the pharate pupae in B. sakabei had vein trachea distributions that could be compared with that of the reduced wing lobe of the female. 

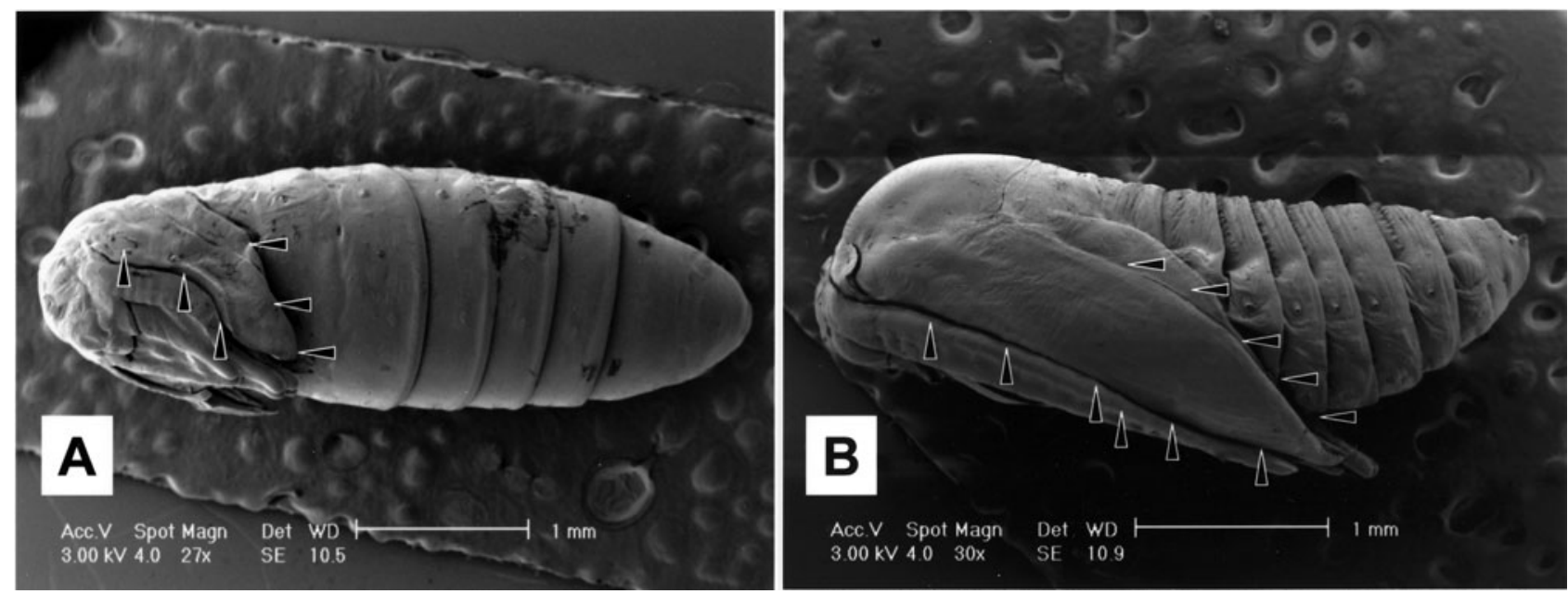

Fig. 3. Scanning electron micrographs of female (A) and male (B) pupae of Bacotia sakabei. Anterior is left. Arrowheads indicate forewing cases. Scale bars: $1 \mathrm{~mm}$.

\section{Histological observations}

For histological observations, the wing imaginal discs of larvae and pupal wings were removed and fixed in Karnovsky's fixative $(2 \%$ paraformaldehyde $+2.5 \%$ glutaraldehyde), buffered with $0.1 \mathrm{M} \mathrm{HCl}$-sodium cacodylate. They were post-fixed with $2 \%$ osmium tetroxide, dehydrated in a series of ethanol and propylene oxide and embedded in Epon 812 (TAAB). Semi-thin sections $(1 \mu \mathrm{m}$ thick $)$ of the wing discs were prepared on a rotary microtome, mounted on microscope slides and stained with Azur B. Slide-mounted tissues were observed using a NIKON OPTIOHOT microscope.

\section{Scanning electron microscopy}

SEM was used to examine the structure of pupae in both sexes of $B$ sakabei. Samples were fixed in Karnovsky's fixtative, post-fixed in $2 \%$ osmium tetroxide, preserved in $90 \%$ ethanol and dehydrated in a graded series of ethanol (up to $100 \%$ ). After critical-point drying, the samples were coated with platinum. Scanning electron micrographs were taken with a SEM (XL30CP, Philips).

\section{Transmission electron microscopy}

In preparation for TEM, wing discs were embedded in Epon 812 and sectioned $(0.12 \mu \mathrm{m}$ thick) using an ultramicrotome with a diamond knife. Sections were placed on No. 150 grids (Nisshin EM, Tokyo, Japan), stained with $4 \%$ uranium acetate for 5 min and then $0.4 \%$ lead citrate for $10 \mathrm{~min}$, and viewed using a JEM 1010 electron microscope (JEOL, Japan) at $80 \mathrm{kV}$.

\section{RESULTS}

\section{Adult females}

Strictly speaking, adult females of the three winglesslegged species have vestigial and nonfunctional wings, and thus are not completely wingless. The adult female of Taleporia trichopterella is dark brown, and its wings are very small (Fig. 2A, arrow). The adult female of Bacotia sakabei is light brown and the vestigial wings are stickshaped (Fig. 2B, arrow). The adult female of Proutia sp. is reddish brown, and its vestigial wings are paddleshaped (Fig. 2C, arrow).

\section{Pupae of both sexes}

For B. sakabei used in the SEM study, the body length of the male pupa was $3.8 \mathrm{~mm}$ and of the females $4.1 \mathrm{~mm}$ (Fig. 3). The female pupal wings in all three species are much reduced (Figs 4A-C). Their length is about $0.8 \mathrm{~mm}$ in T. trichopterella (Fig. 4A), $1.0 \mathrm{~mm}$ in B. sakabei (Fig. 4B) and $1.0 \mathrm{~mm}$ in Proutia sp. (Fig. 4C). In contrast, the pupal wings of the males are well developed (Figs $4 \mathrm{~A}-\mathrm{C})$, and in all three species the forewing length is about $3.0 \mathrm{~mm}$.

\section{Wing imaginal discs in females}

To study female wing degeneration in B. sakabei, the development of wing discs during the last-larval instar in females was observed by dissection. The development of wing discs progresses in the same way for both sexes until the beginning of the prepupal stage of the last instar. The wing discs then grow and enlarge in the last-larval instar and prepupal stages. In the female of this species, several characteristic features of wing reduction were observed. In the middle stage of the last-larval instar (Fig. $6 \mathrm{~A})$, the wing imaginal discs were oval in shape. In the late stages of the last-larval instar, the wing discs enlarge (Fig. 6B) and become surrounded by peripodial epithelia (Fig. 6B, arrowhead). At the beginning of the prepupal stage in the last instar (Fig. 6C), the wing epithelia evaginate and proliferate to form the wing lobe. In the middle of the prepupal stage of the last instar (Fig. 6D), however, the wing lobes decease slightly in size. A high magnification image (Fig. 7) shows apoptotic body-like structures in some cells of the wing epithelia (arrows). This suggests that apoptotic cell death occurs in the wing lobes, although there are normal nuclei in the wing epithelia (Fig. 7, n). At the stage just before the pupation of female larvae proliferation of the wing lobes stops (Fig. 8A) and the wing epithelia secrete a new pupal cuticle (Fig. 8A, arrow). Very few tracheae were observed in the wing lobes of females (Fig. 8A, t). In contrast, at the stage just before pupation in males (Fig. 8B) the wing lobes are larger than in females, and secrete a new pupal cuticle 

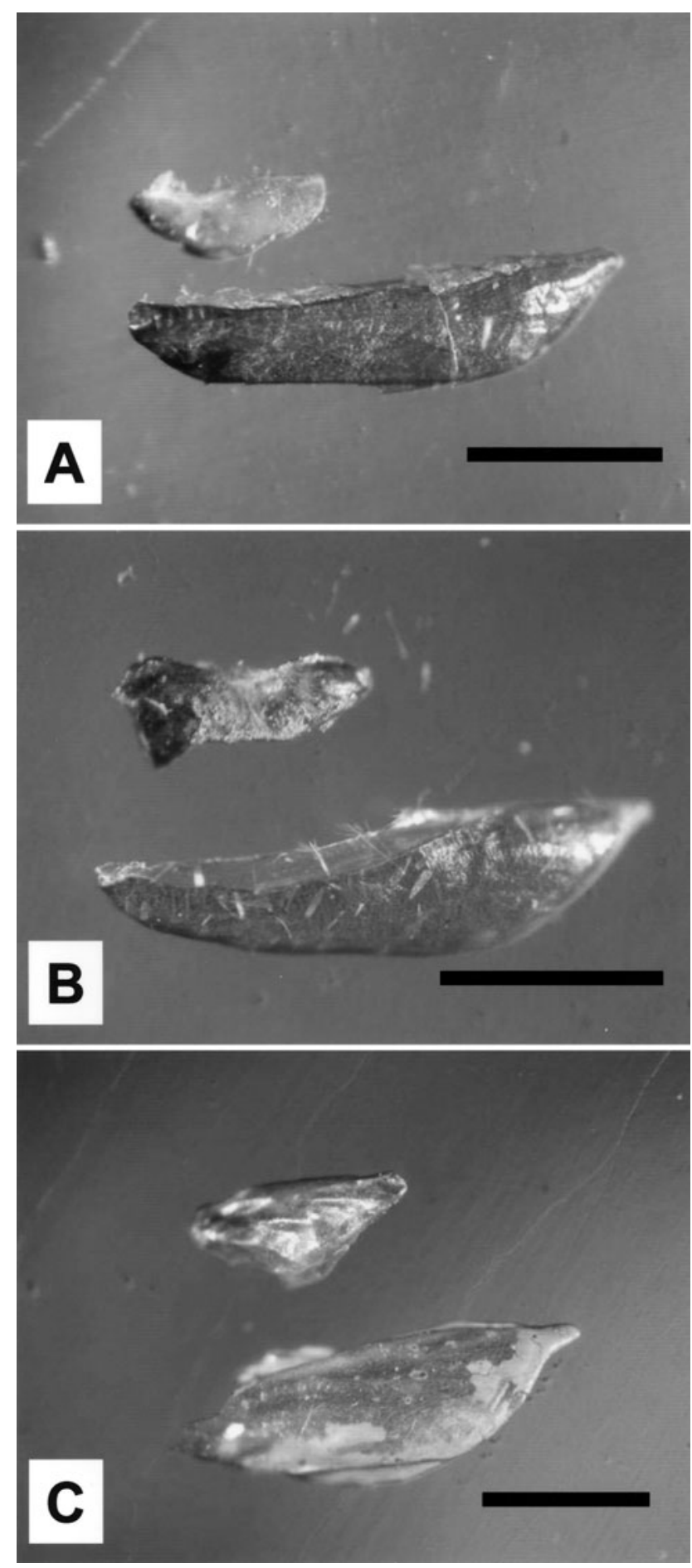

Fig. 4. Female (upper) and male (lower) forewing cases removed from pupae. A - Taleporia trichopterella; B - Bacotia sakabei; C - Proutia sp. Scale bars: $1 \mathrm{~mm}$. Female forewing cases of each species become smaller during the prepupal stage.

(Fig. 8B, arrow). Many tracheae were observed in the wing lobes of males (Fig. 8B, t). In females of the other two species, T. trichopterella and Proutia sp., the wing epithelia secrete a new pupal cuticle just before pupation (Figs 8C-D, arrows).

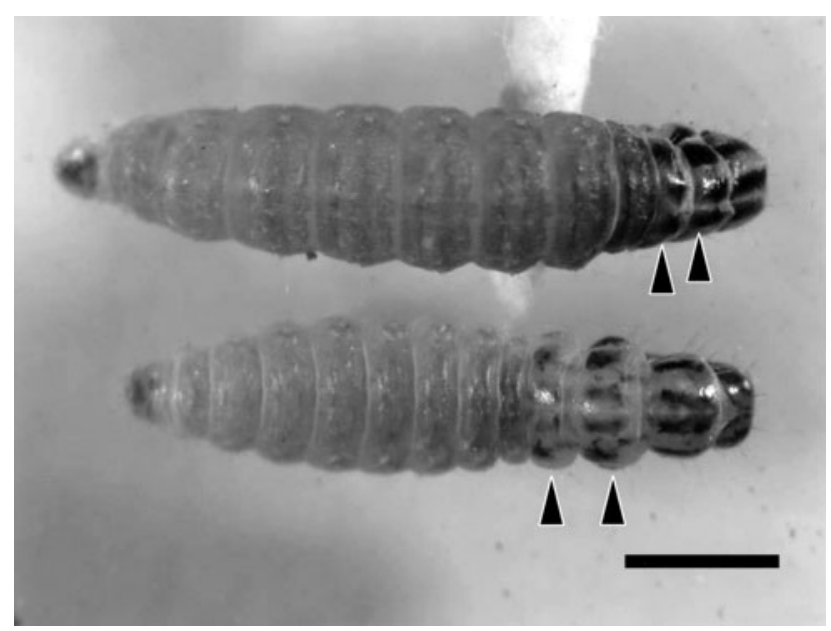

Fig. 5. Female (upper) and male (lower) larvae of Proutia sp. at a late last-instar stage. The body length is about $9 \mathrm{~mm}$ in females and $8.0 \mathrm{~mm}$ in males. Arrowheads indicate the mesothorax (right) and metathorax (left). Scale bar: $5 \mathrm{~mm}$.

\section{Pupal wings of females}

Male pupae of T. trichopterella, B. sakabei and Proutia sp. have well developed wings, whereas the females have vestigial wings (Fig. 4A-C). In the female pupa, we confirmed that the three main wing trachea, i.e., Radius, Media and Cubitus, extended nearly to the margin of the wings (Figs 9A-C). During the pupal stage (days 0 and $1)$, the wing epithelia of both males and females are attached to the pupal cuticle. On day 2 ( $48 \mathrm{~h}$ after pupation), the female wing epithelia in all three species began to degenerate after the wings were withdrawn from the pupal wing case (Figs 9D-F).

In the wingless tussock moth, Orgyia leucostigma, epithelial contraction and presence of phagocytes coincide with a period of extensive cell death (Nardi et al., 1991). In our study, the epithelia of females in all three species are monolayered and phagocytotic hemocytes are in the hemocoel between the upper and lower epithelial layers (Figs 10A-C). Transmission electron microscopy revealed that apoptotic cell death occurs in the pupal wings of females (Figs 10D, E). Wing degeneration becomes evident as soon as wing epithelia retract from the pupal cuticle in females. Condensed chromatins, which are related to apoptotic cell death, are observed in the wing epithelia of females (Fig 10D, arrows). These observations strongly suggest that female wings are further reduced in size by both apoptosis and phagocytosis. This is also considered to be due to apoptotic cell death. These results indicate that the female-specific wing degeneration in these wingless-legged bagworm moths, caused by apoptosis, occurred at two stages, in the prepupal stage of the last instar and the pupal stage.

\section{DISCUSSION}

In the present study, the process of wing formation and degeneration in the females of three wingless-legged species was investigated using scanning and transmission microscopy. In particular, this revealed, for the first time, 

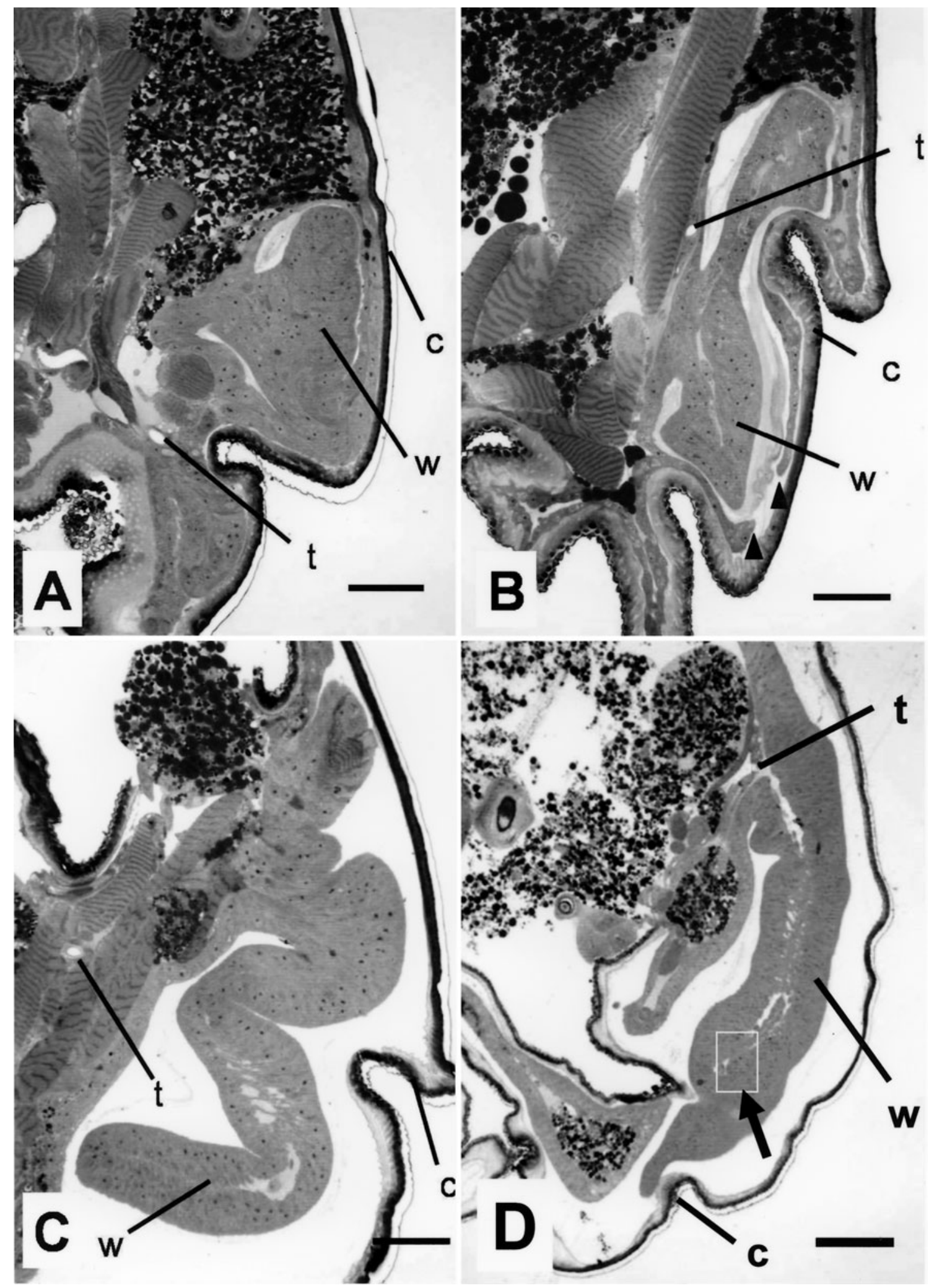

Fig. 6. Cross sections of the female wing lobe (wing disc) of Bacotia sakabei. Sectioned (A) half way through the last larval instar; (B) late in the last larval instar; (C) early in the prepupal stage of the last instar; (D) half way through the prepupal stage of the last instar. Arrowheads indicate peripodial epithelia. White square indicates the area depicted in Fig. 7. The wing lobes deceased in size half way through the prepupal stage of the last instar (D). w - wing disc; $t$ - trachea; c - cuticle. Scale bars: $50 \mu \mathrm{m}$.

that wing degeneration occurs in two stages, first during the larval and then the pupal stage, as shown in Fig. 11. During the prepupal stage of the last instar, the female wing discs evaginated and then degenerated due to apoptosis (Fig. 7). In the pupal stage, the wings of females degenerated further due to apoptosis (Fig. 10). 


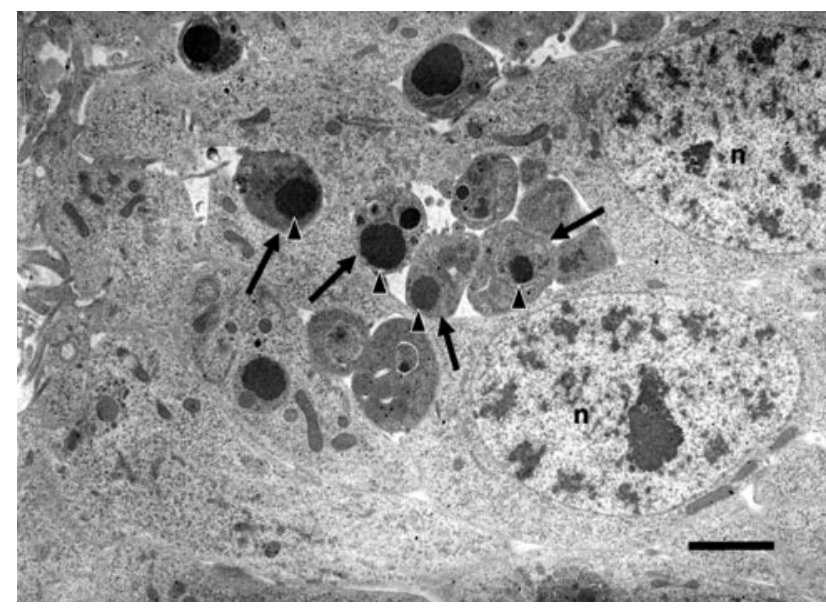

Fig. 7. Transmission electronmicroscope micrograph of the female wing lobes of Bacotia sakabei half way through the prepupal stage of the last instar. High magnification image of the central part of a wing lobe. Note that the apoptotic-body-like structure (arrow) contains condensed nuclei (arrowheads), not yet ingested by phagocytes. Normal nuclei are also present (n). Scale bars: $2 \mu \mathrm{m}$

\section{Wing reduction in psychid moths}

Saigusa (1962) discussed the evolution of atrophied female wings in Psychidae from a phylogenic perspective. He graded species of this family $\alpha, \beta, \gamma 1, \gamma 2$ and $\delta$ according to the degree of wing and leg reduction in the female, as mentioned above (Fig. 1). He also concluded that the degeneration of body structures occurred in the order of $\alpha \rightarrow \beta \rightarrow \gamma \rightarrow \delta$. He ranked the genus Eumeta as $\delta$-grade and exhibited the most derived state. Niitsu (2003) investigated the wing degeneration process in Eumeta variegata, and showed that the process was consistent with $\delta$-grade. In this species, the small wing discs of females do not grow, but disappear due to apoptosis during the prepupal stage of the last instar (Niitsu et al., in prep.).

In the present paper, the fine detail of wing reduction in a wingless-legged bagworm moth, Bacotia sakabei, is described. The following are the successive events in the degeneration of the wings in females: (1) Evagination of the wing discs in the prepupal stage of the last instar; (2) Slight degeneration of the wing lobes of the prepupal stage of the last instar; (3) Formation of vestigial pupal wing cases; (4) A simple tracheal system, which consists of three wing tracheae, Radius, Media and Cubitus, extending into the pupal wings; and (5) Degeneration of the pupal wings. Events (1), (3), (4) and (5) were also observed in the other two species studied here, Taleporia trichopterella and Proutia sp. In these species, wing reduction occurs during the larval-pupal metamorphosis. Thus, the wing degeneration in these three winglesslegged bagworm moths, due to apoptosis, occurs in two steps. Thus, the process of wing degeneration by apoptosis in these three species is possibly a widespread phenomenon among wingless-legged bagworm moths. However, the process of wing reduction has not been previously described in holometabolous insects.
The wingless-legged types ( $\beta$-, $\gamma 1$ - and $\gamma 2$-grades) described by Saigusa (1962) are intermediate evolutionary stages in wing reduction. In the present study, it is speculated that these three grades of adult eclosion are adaptation to the unique ecology or life history of species in the family Psychidae. E. variagata, the female of which is completely wingless, has the most derived grade $(\delta)$, and is the most fecund species in this family. Their females never emerge from the larval case, and lay about 3000 eggs within the case. To explain the evolutionary advantages of the winglessness of $\delta$-grade, it is speculated that nutritional resources normally used for flight by the female may be have been reallocated to egg production. Some studies of wing polymorphism have revealed numerous selective tradeoffs in the reproductive potentials of winged versus flightless forms (Wagner \& Liebherr, 1992). We hypothesize that the behaviour of laying eggs in the larval case with the aid of their long ovipositor provides the selective advantage for the evolution of wing loss in females of bagworm moths. The present results also show that wing reduction in the winglesslegged bagworm moths is not due to classical neoteny, but occurs through apoptosis. The observations on postembryonic female development reveal that larval wing discs form initially, but are destroyed during the prepupal stage of the last instar and pupal stage. Neoteny is generally defined as direct retainment of juvenile characters (Matsuda, 1979), and thus also the completely wingless bagworm moths ( $\delta$-grade) cannot be considered a clear case of neoteny because the complete lack of wings arises through ontogenetic rudimentation of larval wing anlagen. Niitsu (2003) report on the vermiform female adult of Eumeta is the only one that supports this interpretation. Lokki et al. (1975) studied parthenogenesis in the psychid-moth Solenobia triquetrella, the female of which is flightless. Nüesch (1947) studied the process of female wing reduction in this species.

\section{Wing reduction in Lepidoptera}

In Lepidoptera, wing reduction in the female is known to occur in Geometridae, Lymantriidae, Psychidae and some other families (Hackmann, 1966; Common, 1970; Hamilton, 1978; Matsuda, 1979), and there are some studies on the pattern of female-specific wing reduction (Sattler, 1991; Heppner, 1991). In the female of the psychid Pachytelia sp. (Fedotov, 1939), and another psychid, Eumeta variegata (Niitsu, 2003), the development of the wing disc is suppressed in an early larval instar. However, in another psychid, Fumea casta (Nüesch, 1947), the tussock moth Orgyia leucostigma (Nardi et al., 1991), and the winter moth Nyssiodes lefuarius (Niitsu, 2001), female wings form initially but are later destroyed by apoptosis. In N. lefuarius, female wing discs are fully developed but are destroyed suddenly in the late pupal stage by apoptosis (Niitsu, 2001). As the differentiation of imaginal discs progresses, a large number of dying cells appear within the epithelia of wings (Quennedey \& Quennedey, 1990; Nardi et al., 1991; Sameshima et al., 2004). However, the molecular and cellular mechanisms 


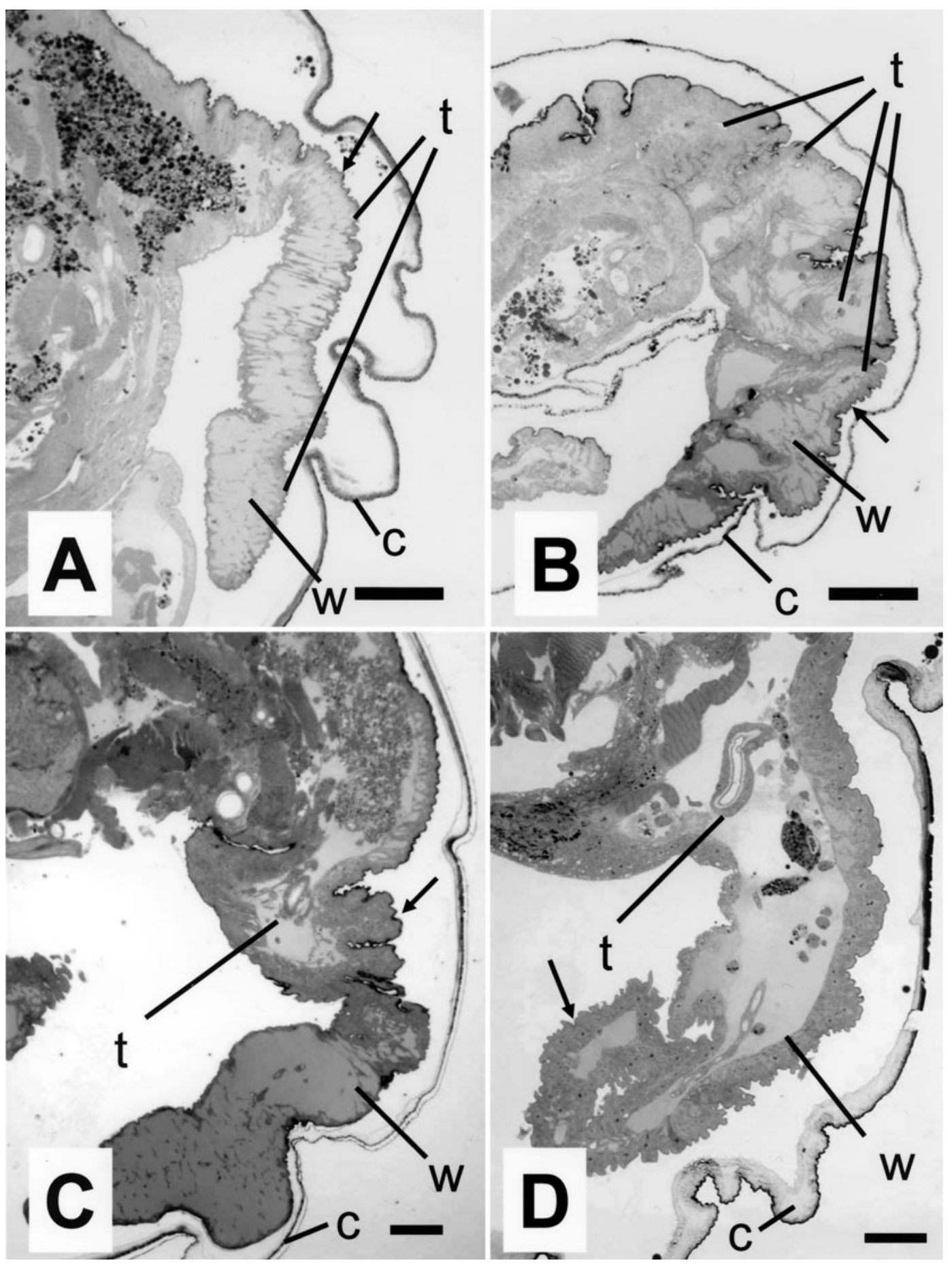

Fig. 8. Cross sections of a late-female prepupa of the last instar (A) and late-male prepupa of the last instar (B) of Bacotia sakabei. Cross sections of the female prepupa in the last instar of Taleporia trichopterella (C) and Proutia sp. (D). All figures show evaginated wing lobes. Note the lamination of the new pupal cuticle (arrows). Many tracheae are present in the male prepupa of $B$. sakabei. $\mathrm{w}$ - wing lobe; $\mathrm{t}$ - trachea. Scale bars: $50 \mu \mathrm{m}$.

causing female-specific winglessness are not yet understood. Lobbia et al. (2003), report that female-specific wing degeneration in Orgyia recens is induced directly by ecdysteroids (20E and E) in pupal wing culture. However, the fine details of the endocrinological basis of wing reduction are unknown.

The present study shows that secondary wing reduction in three wingless-legged bagworm moths belonging to $\beta$-, $\gamma 1$ - and $\gamma 2$-grades is due to apoptosis occurring during larval and pupal stages. Hence, all wingless bagworm moths should not be considered to be neotenous. The results of our study suggest that the intermediate types of wing reduction caused by apoptosis might be common to all wingless-legged bagworm moths of the family Psychidae. 

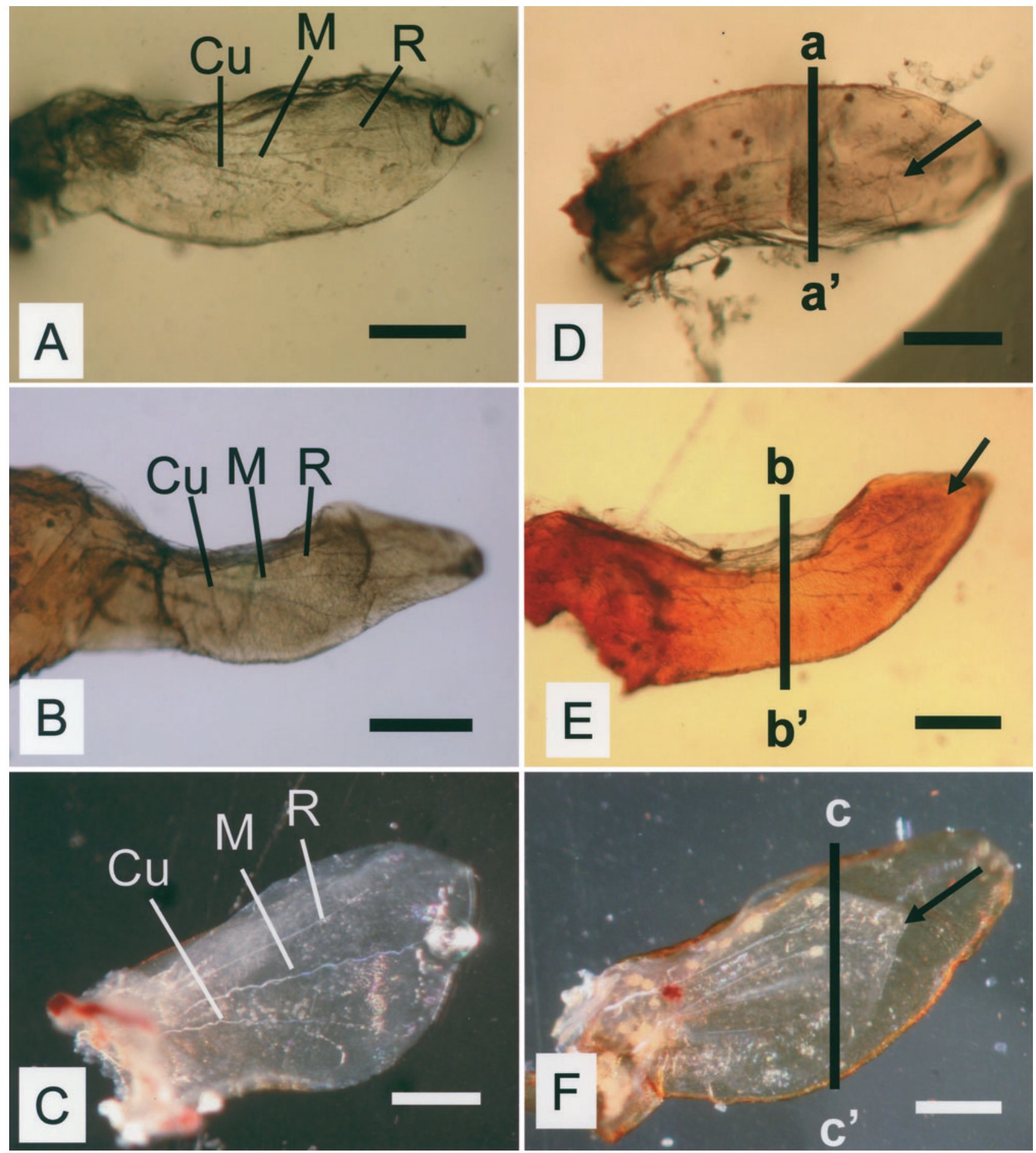

Fig. 9. Morphological changes in female pupal forewings from $0(\mathrm{~A}-\mathrm{C})$ to $48 \mathrm{~h}(\mathrm{D}-\mathrm{F})$ after pupation, Figs A-C show female forewings dissected from pupae just after pupation. Pupal wings of females have a much simpler tracheal system than those of males. Figs D-F shows degenerated wing epithelia (arrows) in wing cases. Arrows indicate the distal end of the degenerated wing epithelia. a-a', b-b', and c-c', levels of the sections depicted in Figs 9D-F. Scales are not yet formed on the wing epithelia. Taleporia trichopterella (A, D), Bacotia sakabei (B, E), Proutia sp. (C, F). R - Radius; M - Media; Cu - Cubitus. Scale bars: $200 \mu \mathrm{m}$.

ACKNOWLEDGEMENTS. We warmly thank K. Kudo (Tokyo), N. Bito (Nagoya City) and S. Koshino (Hannan City) for their help and advice in collecting samples. We are also grateful to M. Sugimoto and T. Saigusa of Kyushu University for the identification of psychid moths. Thanks also to I. Uemura (Tokyo Metropolitan University), T. Shirai (Tokyo University of Agriculture, T.U.A.), A. Kogure (T.U.A.), and A.
Miyaki (T.U.A.) for their technical support with the electron microscopy.

\section{REFERENCES}

ANDERSEN N.M. 1997: Phylogenetic tests of evolutionary scenarios: the evolution of flightlessness and wing polymorphism in insects. Mem. Mus. Natl. Hist. 173: 91-108. 

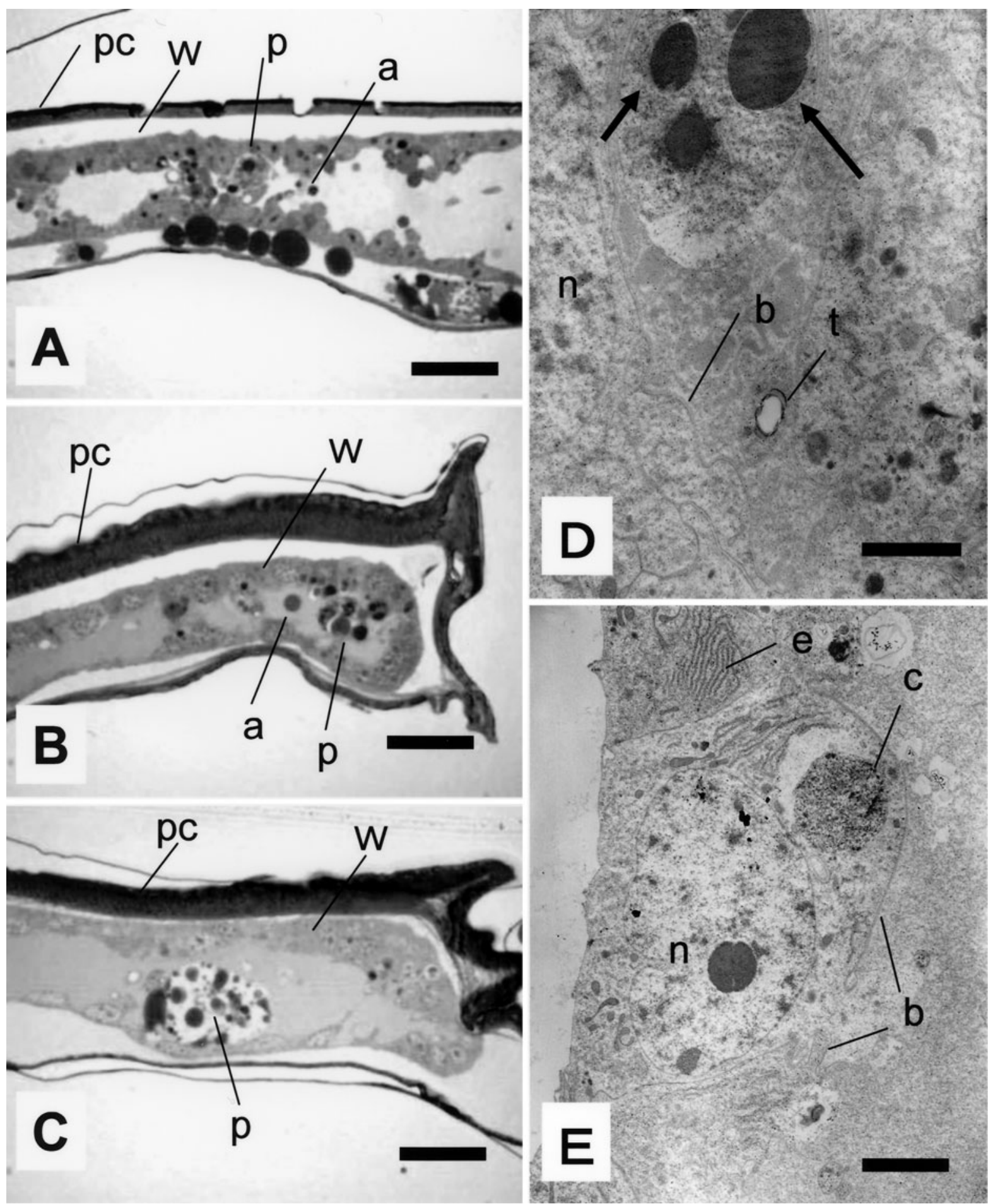

Fig. 10. Wing degeneration in female pupae of the wingless-legged bagworm moths. Cross sections of female pupal wings $48 \mathrm{~h}$ after pupation (A-C). Electron micrographs of the female pupal wings of Bacotia sakabei $48 \mathrm{~h}$ after pupation (D-E). Phagocytosis is occuring in the distal area (A-C). The pupal wing epithelia are detached from the pupal wing cuticle and reduced due to apoptosis and phagocytosis $(\mathrm{A}-\mathrm{C})$. Condensed chromatin and basal lamina are present (D). Endoplasmic reticulum (e) and fragmented cells can be seen (E). (A) Taleporia trichopterella, (B) Bacotia sakabei, (C) Proutia sp. p - phagocytotic haemocytes; pc - pupal wing cuticle; $w$ - pupal wing epithelium; $a$ - autophagic vacuoles; $b$ - basal lamina; $c$ - fragmented cell; $n$ - nucleus; e - endoplasmic reticulum. Scale bars: $20 \mu \mathrm{m}$ for A-C and $2 \mu \mathrm{m}$ for D-E.

Common I.F.B. 1970: Lepidoptera (moths and butterflies). In Mackerras I.M. (ed.): The Insects of Australia. Melbourne Univ. Press, Melbourne, 866 pp.

DAVIS D.R. \& Robinson G.S. 1999: The Tineoidea and Gracillarioidea. In Kristensen N.P. (ed.): Lepidoptera, Moths and
Butterflies, Evolution, Systematics, and Biogeography. Handbook of Zoology IV. Arthoropoda: Insecta Part 35, Vol. 1. Walter De Gruyter, Berlin, pp. 91-117. 


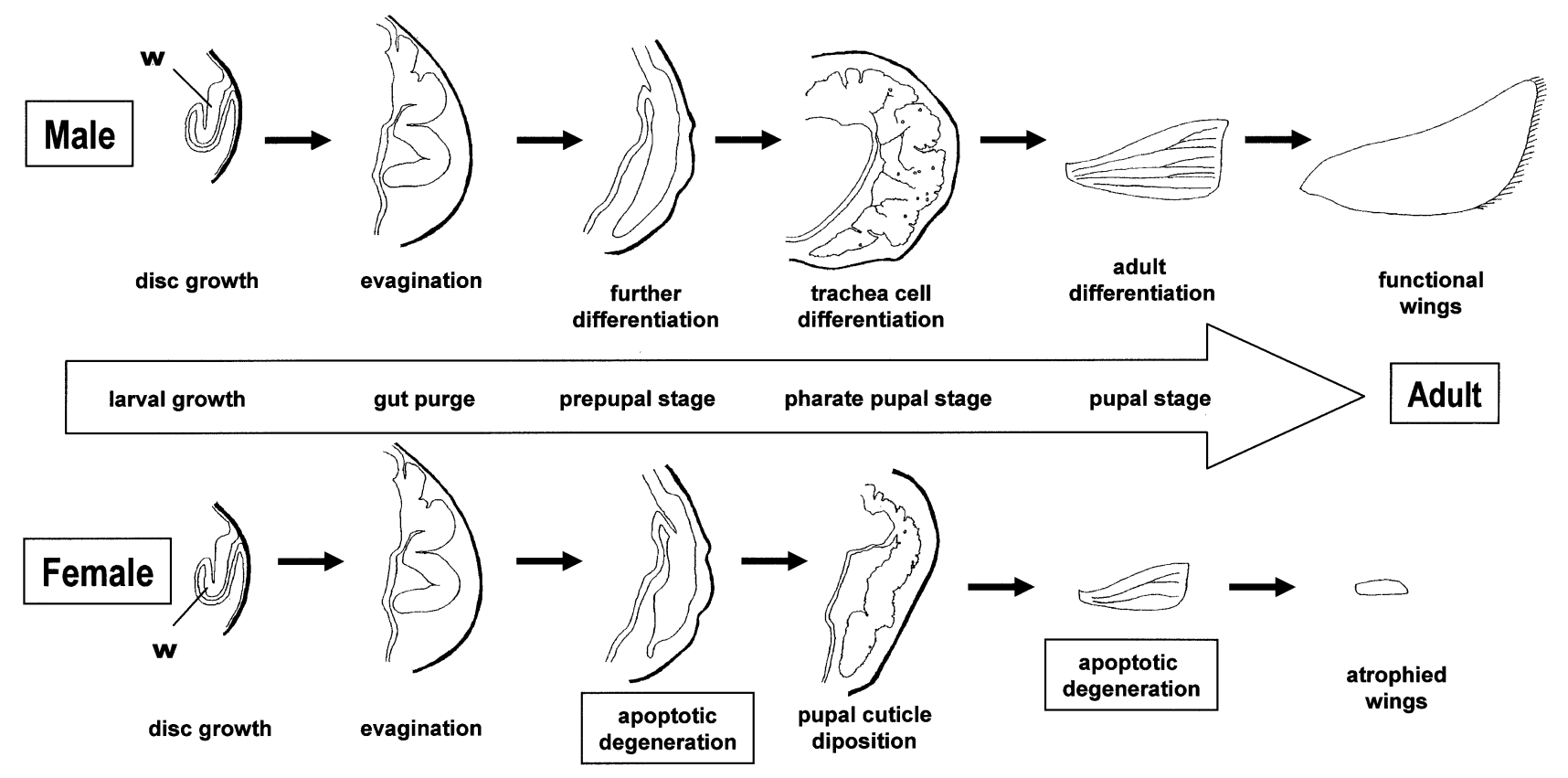

Fig. 11. Schematic diagram of differential wing formation and degeneration in the wingless-legged bagworm moths. In females, wings degenerate by apoptosis in the larval and pupal stages. $\mathrm{w}-$ wing discs.

EnTwistLe P.F. 1963: Observations on the biology of four species of Psychidae (Lepidoptera) on Theobroma cacao L. in western Nigeria. Proc. R. Soc. Lond. (A) 38: 145-152.

Fedotov D.M. 1939: On the phenomenon of regressive changes in some bagworm moths (Psychid). Com. Rend. Acad. Sci. U.R.S.S. 24: 616-619.

Fristrom J.W., Fristrom D.K., Fekete E. \& Kuniyuki A.H. 1977: The mechanism of evagination of imaginal discs of Drosophila melanogaster. Am. Zool. 17: 671-684.

HaCKMANN W. 1966: On wing reduction and loss of wings in Lepidoptera. Notul. Entomol. 46: 1-16.

Hamilton W.D. 1978: Evolution and diversity under bark. In Mound L.A. \& Waloff N. (eds): Diversity of Insect Faunas, Symposia of the Royal Entomological Society of London, No. 9. Blackwell Scientific, Oxford, pp. 154-175.

HePPNER J.B. 1991: Brachyptery and aptery in Lepidoptera. Trop. Lepid. 2: 11-40.

Kawasaki H. \& Iwashita Y. 1987: Differentiation of wing disc of the fifth larval instar of Bombyx mori in vitro culture condition. J. Seric. Sci. Jpn 56: 65-71 [in Japanese, with English abstr.].

Lobbia S., NitTsu S. \& FujIwara H. 2003: Female-specific wing degeneration caused by ecdysteroid in the Tussock Moth, Orgyia recens: Hormonal and developmental regulation of sexual dimorphism. J. Insect Sci. 3: 1-7.

Lokki J., Suomalainen E., Saura A. \& Lankinen P. 1975: Genetic polymorphism and evolution in parthenogenetic animals. II. Diploid and polyploid Solenobia teriquetrella (Lepidoptera: Psychidae). Genetics 79: 513-525.

Matsuda R. 1979: Abnormal metamorphosis and arthropod evolution. In Gupta A.P. (eds): Arthropod Phylogeny. Van Nostrand Reinhold, New York, pp. 137-256.

Milner M.J., Bleasby A.J. \& Kelly S.L. 1984: The role of the peripodial membrane of leg and wing imaginal discs of Drosophila melanogaster during evagination and differentiation in vitro. W. Roux's Arch. Dev. Biol. 193: 180-186.
Nardi J.B., Norby S.-W. \& Magee-Adams S.M. 1987: Cellular events within peripodial epithelia that accompany evagination of Manduca wing discs: conversion of cuboidal epithelia to columnar epithelia. Dev. Biol. 119: 20-26.

Nardi J.B., Godfrey G.L. \& Bergstrom R.A. 1991: Programmed cell death in the wings of Orgyia leucostigma. $J$. Morphol. 209: 121-131.

NIITSU S. 2001: Wing degeneration due to apoptosis in the female of the winter moth, Nyssiodes lefuarius. Entomol. Sci. 4: $1-7$.

NIITSU S. 2003: Postembryonic development of the wing imaginal disc in the female wingless bagworm moth, Eumeta variegata (Lepidoptera, Psychidae). J. Morphol. 257: 164-170.

NÜESCH H. 1947: Entwicklungsgeschichtliche Untersuchungen über die Flügelreduktion bei Fumea casta und Solenobia triquetrella und Deutung der Solenobia-Intersexen. Arch. J. Kraus-Stiftung. 22: 221-293.

QuenNedy A. \& QuenNedy B. 1990: Morphogenesis of the wing anlagen in the mealworm beetle Tenebrio molitor during the last larval instar. Tissue Cell 22: 721-740.

Roff D.A. 1990: The evolution of flightlessness in insects. Ecol. Monogr. 60: 389-421.

SAIGUSA T. 1962: On some basic concepts of the evolution of psychid moths from the points of view of the comparative ethology and morphology Tyo to Ga. 12: 120-143 [in Japanese, with English abstr.].

Sameshima S., Miura T. \& Matsumoto T. 2004: Wing disc development during caste differentiation in the ant Pheidole megacephala (Hymenoptera: Formicidae). Evol. Dev. 6: 336-341.

SATTLER K. 1991: A review of wing reduction in Lepidoptera. Bull. Br. Mus. Nat. Hist. (Entomol.) 60: 243-288.

WAGNER D.L. \& LieBHERR J.K. 1992: Flightlessness in Insects. Trends Ecol. Evol. 7: 216-220.

Received April 20, 2007; revised and accepted January 8, 2008 